Article

\title{
Class, Style and Territory in the Drari Microcultures of Brussels
}

\author{
Mattias De Backer 1,2 (D) \\ 1 Department of Criminology, KU Leuven, Oude Markt 13, 3000 Leuven, Belgium; \\ mattias.debacker@kuleuven.be \\ 2 Department of Sociology, Université de Liège, Place du 20 Août 7, 4000 Liège, Belgium
}

Received: 30 May 2019; Accepted: 25 August 2019; Published: 11 September 2019

\begin{abstract}
Much like Parsons's notion of "youth culture," the tradition of subculture developed by the Birmingham School was criticised as being too romantic, too general, and too dependent on a simplistic model based on the inside/outside binary. Since the 1990s, "post-subcultural" studies have developed which prefer to focus on agency rather than structure. A "third school" of youth cultural studies focused on medium sizes groups and their attachment to place, which they called "microcultures". This paper, drawing from fieldwork undertaken in Brussels between 2013 and 2016 with young people, studies members of the Brussels "street culture" called the drari, while zooming in on the combinations of personalities, the events they share and the locations they make their own. Specifically, this paper argues that the drari microculture does not fit in the binary model of (post-)subcultural theory, nor in the criminological frame of urban youth gangs, by focusing on the affective and class-related phenomena internal to their practices of territory-building.
\end{abstract}

Keywords: subcultures; microcultures; territory; class; Brussels youth

\section{Introduction}

A whole set of "-cultures" has been coined by sociologists to refer to young people. "Youth culture" was first used as a concept by Talcott Parsons [1] in order to describe a set of professedly unique, distinctive patterns among young people, which emphasised values such as hedonism, consumption and irresponsibility. Youth is viewed by Parsons as a unitary adolescent subculture transcending all other cultural attachments to home, neighbourhood or class, expressing an antagonistic relationship to the social order [2] (p. 190).

Building on earlier work by David Matza, Albert Cohen and the Chicago School, the Birmingham Centre for Contemporary Cultural Studies (CCCS) developed a structuralist framework for understanding youth culture. Their work was based, for the most part, on ethnographic studies that focused on the rituals that youth create within the context of popular culture consumption and performative practices [3]. The basic assumption is that "youth subcultures belong to the working class, deriving from the experience of subordination. Subcultural activity is interpreted as a form of symbolic politics to particular class and cultural experiences" [4] (p. 6). Phil Cohen [5] saw youth cultural style as a reaction of young people against the circumstances of their time. Style-production was effectively a weapon in the ongoing class struggle. Hence, the word "sub-culture", which is a responsive, bottom-up initiative against "hegemonic" culture and its values. Importantly, in his studies of juvenile gangs, Cohen found that it was mostly lower-class young men that were engaged in subcultures in which the display of deviance is associated with status within these groups. In line with social identity theory [6,7], the categorisation by the outside world of a group as deviant will reinforce this group's identity. 
Cohen's paper was the direct impetus for Hall and Jefferson's seminal book Resistance Through Rituals [8], dedicated to a concern with the structural and cultural origins of British post-World War II youth subcultures. Cultures were viewed as expressive of social class and social organisation grounded in Marxist theory. Central to their vision of subcultures was the concept of "resistance", influenced by Antonio Gramsci's theory of hegemony. In his theory, Gramsci assumes that dominant social groups, whose cultural capital is the largest, create and delineate a hegemonic culture in order to reinforce their own social position at the expense of others. The work of the CCCS emphasised the principle that within society there is a continuous struggle over the distribution of "cultural power". The ruling classes are able to not only rule and dominate the subordinate classes' behaviour but also to obtain their consent to be ruled and dominated [9] (p. 540). Research inspired by the Birmingham School therefore tends to focus on groups of youngsters such as punks, mods or hippies.

Three main criticisms can be made on this framework, synthesised by Daskalaki and Mould [10] as: too romantic, too general and too dependent on a simplistic inside/outside binary. Firstly, we need to be careful not to over-romanticise the intention of "subcultural" groups to resist dominant social norms. As Jenks [11] remarks, the CCCS normalised youth reaction and protest in post-war Britain by rendering it fully intelligible in bounded subcultures. "Beyond this analytical capture they then went on to ascribe such youthful agitation "grown-up" political purposes" (p. 130). Thornton [12], similarly, comments that the CCCS conception of youth subcultures is over-optimistic while Maira and Soep [3] point out that youth regularly serves to personify a given society's deepest anxieties and hopes. To counter this, Malbon [13] argues that we need to rethink "resistance" in that it does not necessarily challenge the dominant culture, rather it is located in everyday, unnoticeable subtleties, in "routine transgressions" [14] (p. 29). It may less be young people's intention to challenge the mainstream than to carve out a niche for themselves [15].

Secondly, the fragmentation and heterogeneity of growing up, even within a single geographical context, has made the use of blanket terms such as youth culture and subculture untenable: "there is no single defining youth culture, but a diversity of larger and smaller groups that frequent one another for a certain period of time, during which they share a number of characteristics" [16] (p. 88). These terms homogenise the practices of youth and fail to allow for local variation as well as different degrees of commitment [17]. "Young people no longer depend on subcultural affirmations for the construction of their identities (if indeed they ever did) but construct lifestyles that are as adaptable and as flexible as the world around them" [2] (p. 213). As [18] suggests, there is now an overwhelming body of evidence that demands both a reinterpretation and a redefinition of youth culture. Instead of seeing young people as a group apart, all sharing the same values, their diversity and difference need to be acknowledged.

Thirdly, the term divides populations in "inside" and "outside" subcategories, without giving much attention to what happens at the interfaces. From within the CCCS, Willis [19] (pp. xlv-xlvi) writes that " $[t]$ here has not been a vigorous analysis of the status of the culture a sub-culture is supposed to be 'sub' to. The notion implies a relative positioning which seems to give an altogether misleading sense of absoluteness and dominance of the main culture." [20] (p. 69), similarly remarks that the term has inched its way into everyday speech and it has been a greater success socially than intellectually: "[t]here are (.. ) the ambiguities built into the very word-does "sub" make this type of culture simply a segment of a larger culture, or is it something subordinate to a dominant culture, or is it something subterranean and rebellious, or is it substandard, qualitatively inferior?" Interestingly, in his criticism of post-subcultural theory, [4] (p. 11) seems to suggest that invisibility is a key component for a subculture, which would make the case for understanding the "sub" as something that refers to a phenomenon which is below the waterline, not noticed by law enforcement, media or politicians.

Since the 1990s, studies concerning young people have given rise to terms such as "club cultures" [12,21] "nightlife youth culture" [22], "neotribes" [23], "lifestyles" [24], "scenes" [25,26] or, more generally, "post-subcultures". Postmodern subcultural theories give precedence to individual 
agency and meaning-making rather than group identity, to transgression rather than "resistance", to fluidity and heterogeneity rather than social structure and to consumerism and hedonism rather than class struggle. Commentators such as Miles [24] (pp. 159-160) argue that "[y] oung people no longer depend on subcultural affirmations for the construction of their identities (if indeed they ever did) but construct lifestyles that are as adaptable and as flexible as the world around them." Bennett [27] (p. 599) criticises classic subcultural theorists for claiming to investigate issues of social class, which "are in fact examples of the late modern lifestyles in which notions of identity are 'constructed' rather than 'given'." Thornton [12] considers subcultures as apolitical groups, arguing that mass media and culture industries are central in subcultural formation. Redhead [21] announces the end of subcultures and argues they are superficial and hedonistic. These contemporary studies of youth culture claim to still pay attention to classic subcultural analyses (such as class and resistance), while simultaneously considering the increasing speed of cultural innovation and diversity among young people, but there is some debate about the veracity of these claims (see [4]).

Rather independently of the resistance-focused and Marxist-inspired subcultural debates in sociology, an alternative track of youth culture analysis developed with a specific focus on small interacting units. To a certain extent, debates between subcultural and post-subcultural theorists are stuck in opposites; they either promote social structure or individual agency, homogeneity or heterogeneity, fixity or fluidity. However, "small groups have been largely ignored as a topic in their own right, (...) at a crossroads where agency meets structure" [28]. In this "third school" of youth culture research, small groups are assumed to have a culture of their own, an "idioculture" or "self-culture" [29]. Wulff [30] refers to "microcultures" as flows of meaning managed by small groups of people that meet on an everyday basis [31]. Hannerz [21] (p. 19; my italics) remarks that a "conception of culture without sensitivity to scale has consequences for the study of the smaller slices of human life as well as for the understanding of wider wholes." Although we are inclined to give priority to more generalised versions of meaning and higher scales, at the lowest level, we may find shared meanings directly tied to specific, likewise shared, experiences of people, settings, and events, which he calls "microcultures".

Quite similarly, Matthews et al. [32] define "microculture" as follows: "microcultures are created by combinations of personalities, the locations they make their own and the events they share. Together these provide common and unifying sets of experiences" (p. 196; my italics). Their analysis stresses the importance of places for the production of a microculture: "in this sense, places become imbued with cultural values and meanings, affording not only a sense of identity, but also generating a sense of difference and of being special" [32]. Together, these places form a microgeography, a spatiotemporal map of experience. Blommaert and Varis [33] speak, in this regard, of a "light community": a community which, in a certain setting, is recognisable as a specific community, but without the specific setting and connecting norms the group shatters in a multitude of different identities. What sets these readings apart from classic sociological analyses is the focus on small groups and the sensitivity to scale and place and how these are co-constructing young people's (individual and social) identities. They stress the fluidity and contingency of meaning-making rather than thinking about young people as "'passive' recipients of adult values" whose only activity is limited to "rituals of resistance" [32] (p. 196).

This "third" school of youth culture analysis, by choosing to focus on the cultures of small group, successfully avoids having to choose between the classic structure/agency opposition, yet, they share some characteristics with both subcultural or post-subcultural theory. At first glance, the "microculture" concept is, due to its inherent sensitivity to heterogeneity and fluidity, much more akin to a post-subcultural analysis of youth culture. Indeed, to authors such as Matthews et al. [32], children and teenagers should be considered as part of a multiplicity of (micro-)cultures. However, a sensitivity to place and scale automatically brings discussions of class struggle and resistance back in the picture. As Lefebvre [34] (p. 68) has shown convincingly, the social and the spatial are intensely correlated: "[t]oday more than ever, the class struggle is inscribed in space." On the one hand, "[s]ocial space is allocated according to class, and social planning reproduces the class structure" [35] (p. 106). On the 
other hand, the body acts as a site of resistance which can overturn the way power is reproduced and re-inscribed in space. As Shildrick, Blackman and MacDonald [36] report in the preface to their Special Issue on "Young people, class and place", "when international companies take away the resources and culture of people at the local level (while quoting David Harvey), when young people are excluded from certain cosmopolitan place (while quoting Manuel Castells), it becomes clear that under globalization place is, contra-intuitively, becoming more important "as they experience an increased priority of the specificity of locality. ( . . ) Thus, young people face mounting tensions and surveillance at home, on the street or in the park as they seek to capture what adults already possess, their own place" (p. 459).

In this paper, drawing from ethnographic, participatory fieldwork with young people undertaken in Brussels, I argue that this spatial reading of youth cultures, through Matthews et al.'s [32] "microculture" concept, allows for a subtler understanding of their practices and beyond the binaries of classic and post-subcultural theory. To make this point, the paper zooms in on the drari microcultures in Brussels, their shared experiences, meanings and, most importantly, the "locations they make their own." After a description of their shared identity, expressed in dressing styles or music preference (in line with many subcultural studies), I spend particular attention to how territoriality plays an important role in these young people's feelings of belonging and ownership and in the production of their social identity. Territoriality, as earlier research has shown [37,38], usually implies limited spatial mobility and correlates with low social and cultural capital. Territoriality almost exclusively takes place in deprived neighbourhoods of the city, because the material environment which is magically appropriated and controlled by these social groups is usually owned by private landlords living elsewhere or by the state [39] (p. 65). The analysis will show that the drari share characteristics with classic sociological and criminological concepts such as subcultures (group identity and resistance), post-subcultures (individual identity and lifestyle) and even urban youth gangs (territory and crime/deviance) although their microculture does not entirely coincide with any of them.

\section{Doing Participatory Ethnographic Research with Young People in Brussel}

The fieldwork from which this paper draws was conducted in five Brussels neighbourhoods between 2013 and 2016. It consisted of countless hours of observation in various public spaces, as well as loosely structured interviews and focus groups involving 48 young people between the ages of 11 and 25. Time was spent with young people in the context of youth club activities, youth camps and walks through their home neighbourhoods. Some of these fieldwork activities were also documented by Belgian filmmaker Brecht Vanhoenacker, which eventually led to the documentary La Ville Mon Espace. ${ }^{1}$

In 2017, the Brussels capital region numbered 1,191,604 inhabitants, with estimates adding another 100,000 inhabitants unaccounted for: asylum seekers, students and employees of the European institutions [40]. The Brussels capital region is characterised by an enormous gap between rich and poor. In addition to this social division, the region is also divided across topographic lines, with wealthier areas literally rising above poorer neighbourhoods [41]. This demographic divide takes the form of a sickle-shaped area covering northwest side of the city, which is commonly referred to as the "poverty crescent". The fieldwork for this research took place in five neighbourhoods-Jacht-Jourdan, Chicago, Kuregem, Sint-Guido and Peterbos-of which only the first is located outside the "poverty crescent". These areas were selected because of demographic differences, although their selection was also contingent on the sometimes-coincidental contacts developed with local practitioners. As such, these areas were not necessarily chosen in view of a strictly comparative research design, but rather to provide an insight into the daily life of young urbanites.

1 La Ville Mon Espace was made by Mattias De Backer and Brecht Vanhoenacker. The film is available at http://www.vubtoday. be/nl/content/docu-la-ville-mon-espace-brusselse-jongeren-en-hun-wijk. 
Of course, some of my early intuitions did influence the choice of neighbourhoods in the sense that these areas are marked by clear differences regarding ethnicity and class. When researching the life-worlds of young people and the particular influence of public space on these urbanites, the local context will obviously play a role. Since it literally shapes and constrains the world inhabited by young people, the built environment directly influences their behaviour and social interaction, as well as their affective states and, ultimately, their wellbeing. Additionally, the different demographic constellations of a specific neighbourhood seem to contribute to the production of atmospheres, as the latter are highly contingent on particular spatio-temporalities. Lastly, the choice for a variety of spatial contexts, which do not necessarily coincide with circumscribed neighbourhoods, may invite researchers to engage in some comparative research, although they may also consider the opposite, given that the quest for commonalities only makes sense if there is a sufficient degree of heterogeneity. I therefore believe that it is reasonable to investigate young people's experiences, emotions, actions, habits and movements by "cutting through" the various demographic differences.

Jacht-Jourdan is a lower middle-class area, with a slightly below average income. It is rather diverse in terms of ethnicity, but features lower proportions of North-Africans compared to areas such as Kuregem or Chicago. The Chicago area consists of two very dense neighbourhoods on both sides of the Canal. The area is a typical neighbourhood within the poverty crescent, characterised by a relatively low level of education, high unemployment $(40 \%)^{2}$ and an economic standstill. The Moroccan population accounts for the largest minority in the area. In terms of housing, the situation is dire since residences here are smaller than anywhere else in the entire region.

Kuregem is similar to the Chicago neighbourhood, with an unemployment rate of $40 \%$, and a youth unemployment rate of $55 \%$. The average family size in Kuregem is the largest in the region and its overall population is among the youngest, together with the Chicago area. As far as populations go, Kuregem is an area with a large Moroccan community but there is also a significant number of sub-Saharan Africans. Because of cramped living conditions, limited public space and high density, the situation for young people in Kuregem is dramatic. The Sint-Guido neighbourhood, officially named Anderlecht-Centrum-Wayez, is located at the centre of almost any demographic graph. Although Sint-Guido's housing situation and general outlook are definitely better, the average income remains relatively low, only ranking slightly higher than the very poor areas of Kuregem and Chicago. Peterbos is a lower middle-class residential area. Its centre consists of a series of high-rise social housing blocks, which provided the focus of my fieldwork for this project. Similar to the Chicago neighbourhood, its inhabitants reported a strong sense of community.

During my fieldwork I spoke with 48 young people, either in the context of one-on-one interviews or in focus groups. In terms of their place of residence within the Brussels Capital Region, I interviewed $\mathrm{f}$ participants in Peterbos (Anderlecht), 5 in the Chicago area (Sint-Jans-Molenbeek and downtown Brussels), 15 in Jacht-Jourdan (Etterbeek) and 23 in the Sint-Guido neighbourhood. For the participants interviewed in Sint-Guido, it should be noted that 10 of them lived in the neighbourhood, 8 came from different neighbourhoods across Brussels, and another 6 lived outside the Brussels Region. Regarding ethnic origin, most of the participants were second- or third-generation migrants; only 10 of the participants were born outside Belgium. More than half of the sample groups ( 26 in total) consisted of North-African or Middle-Eastern youngsters, most of whom had roots in Morocco or Tunisia. The other parts of the sample groups consisted of a smaller group of 11 Europeans, comprising 9 "original" Belgians; 1 Italian; 1 Spanish; a group of 10 Sub-Saharan Africans from Congo, Cameroun, Ghana, Angola, Kenia and Rwanda; and 1 youngster with roots in Asia (Pakistan). In terms of gender, 15 of the 48 youngsters were female, most of whom I encountered in the Sint-Guido case study, and 33 were male. Regarding age, the sample consisted of 12 younger teenagers (10-14 years old), 27 older

2 The data on unemployment used in this section were taken from the website http://wijkmonitoring.brussels, which collects all the latest data from the Brussels employment agency Actiris and the Belgian statistics agency Statistics Belgium. The latest unemployment data were collected in 2012. 
teenagers (15-18), and 9 young adults (19-25). In terms of class, the large majority (more than $75 \%$ ) of the young participants were growing up in lower-class families.

Fieldwork in a particular area usually started with exploratory walks and making observations, indicating popular hangouts and other youth spaces (such as youth and sports clubs, and schools) on a paper map that I carried with me. On this map, I would comment on the use of space for the parks and squares I observed, occasionally taking covert pictures. I also spent some time mapping control infrastructures in general and CCTV cameras in particular. After these mappings, I started to establish contact with young people through the social workers at several local youth clubs, gradually building a relationship of trust by working as a voluntary youth worker, cook, driver or general logistic helper. Only then was I able to start discussions on the topic, which was generally introduced as a research project into the lives of young urbanites and their use of public space. For approximately half of the cases I was first able to organise one or two focus groups in the context of which youngsters were asked to draw mental maps (inspired by [42]). These maps were then placed across the middle of the table, providing useful clues that could be picked up during the discussion. The participatory approach allowed for very dynamic and creative discussions, inviting the group to "think with" [43] objects such as maps and pictures.

In a later stage, many of the participants were also interviewed individually, following a loosely structured topics list (divided into seven sections: personal information, description of some hanging spots, the social environment, the neighbourhood, feelings, life-world, dreams and suggestions) -all of the interviews and focus groups were transcribed verbatim, open coded and organised in themes and concepts. In some cases, we had the chance to do a neighbourhood walk in which young people showed us around in their neighbourhood, discussing favourite, avoided or dangerous places and memorable events (see also Breitbart [44]). To conclude the process, I spent many hours walking again through these neighbourhoods, mapping my trajectories using a mobile GPS tracker, while taking pictures and jotting down notes, focusing specifically on my own sensations and emotions, reacting on the environments and changing atmospheres I came across.

\section{The Drari Microcultures}

Several of the boys and young men refer to hanging out as an activity that gives them an identity. As Othmane $(11, \mathrm{~m})$ says, with a smile: "we call ourselves the drari of the neighbourhood." Drari is a street identity among Brussels boys and young men. The term itself is Arab for "children" or "guys" $[45]^{3}$. In Brussels, the term is used predominantly among young people, referring to a street culture that involves a dress-code, haircuts, slang, gestures and behaviours and a set of shared experiences and meanings. These drari express their belonging to this microculture by wearing American trainers and baseball caps, religious garments, particular haircuts and attributes referring to French-spoken rap and hip hop. Dalila (16 f) does not understand why these boys all dress the same: "yes, I see that too. But I don't feel comfortable with it. I wouldn't like it when I see someone with the same clothes as myself. I would want to change mine immediately." She clearly wants to emphasise her being different by wearing unique clothes and does not see how these boys prefer a uniform dress code. Matthews et al. [32] refer to this unique type of dress-code as "emblems of groupness", while observing a group of male teenagers playing football, all wearing wide jeans and baseball caps worn front side backwards. The "groupness", interestingly, is not about an individual expression of aesthetic taste, rather, the emblems show sameness and belonging. It is no coincidence that exactly these boys express such a need, as they are the most affected by stigmatisation and othering. The dress-code seems to suggest that these boys wear their identity as outcasts with pride.

3 In North-Africa, the term is also used to refer to the junior members of a music ensemble and stresses the relation of dependency or subordination of these musicians to the group leader or m'alem [46]. 
What also sets them apart is their main activity: hanging out in public space. This central activity is important and generates a set of "moves", habits and a particular kind of street theatre. During an observation near the Saint-Guidon metro, I write the following:

“on a few places adolescents with North-African roots are bantering, showing off, kickboxing in the air. Their macho behaviour is really typical, not only among adolescent boys but even more so among boys hanging out. It sounds like a generalisation, but the degree in which they copy one another is really impressive" (30 September 2015).

The microculture crystallises in the shared activity of hanging out: "we talk with our mates because we do the same things, we enjoy the same things" (Souhail, 17, m). When asked about popular youth cultures such as graffiti or skating, youth worker Abdel answers "no, that is not the culture of Peterbos" Instead, the neighbourhood is characterised by boys hanging out in different places of the estate at different times of the day, as a routine. The rhythm of their daily routine consists of kicking a ball ("here we play football"), resting near the pitch, hanging out at the local grocery store "at the [building number] 9", having a drink, maybe meeting friends at the metro station.

In the drari-microcultures, aspects of ethnicity, religion and culture are thrown together in a remarkable mélange, because it is not compulsory to be Arab, Moroccan or Muslim for someone to call himself drari (although it is very rare that a girl will call herself that). However, while accompanying these young people in a series of workshops and youth club activities, it becomes clear that fixed categories disintegrate when an appeal is made to other roles and identities. For instance, if a topic such as ethnic identity is discussed, many participants would call themselves "Moroccan", indicating that they consider their ties with their parents' home country at least as important as their Belgian identity. Relevant here is the observation that this allegiance refers to a different scale: while the drari microculture is produced in public space (mostly within the home neighbourhood), this ethnic identity refers to a country abroad. As I have shown elsewhere, ethnicity is temporarily suspended as a meaningful marker of difference while they hang out among themselves [47]; drari microcultural groups can be mono-ethnic but ethnicity is not a structuring variable of its group membership.

What makes the drari a microculture is the fact that their shared culture is contingent on a shared territory or microgeography. Although the term drari is used throughout the Brussels region, drari groups consider themselves different from those from other areas or neighbourhoods. As Souhail $(17, \mathrm{~m})$ says about young people from another neighbourhood: "those of Molem [short for Molenbeek], they are bizarre." Echoing the practices of Brussels youth gangs who mark their territory using tags, drari identify with postal codes and catchy abbreviations of neighbourhoods (e.g., IXL for Ixelles, Molem for Molenbeek, and PTBS for Peterbos), while also using imagination and fiction to create collective identities [48]. Quite similar to the participants in Matthews et al.'s [32] research, young people are aware of which gangs hang out in which neighbourhood, although they are not necessarily perceived as delinquent, rather, they represent clusters of friends "who [share] common visions and interests" [32] (p. 196).

According to Bianca $(18, \mathrm{f})$ "there are multiple types of young people. There are those young people that hang out on the Munt square and go to the library or the theatre and there are those that hang out at Saint-Guidon metro station." She refers to two rather fixed and uniform categories among Brussels youth: those that hang out in the public spaces of their home neighbourhoods and those that do not. It is clear that hanging out at the library or at the square have different moral connotations. Rayane $(17, \mathrm{~m})$ remarks the following:

Me: "You told me that you hang out in the city centre. Tell me something about it."

Rayane: "I don't really hang out. I usually go out to play football or just to talk with some friends when the weather is nice. Sometimes also with my nephew."

At first glance, it seems Rayane distinguishes between hanging out on the one hand and going outside to do something — e.g., football—on the other hand. In reality, he distinguishes himself from 
those boys who hang out all the time and are "no good". Most interviewed boys and girls are well aware of the difference between "harmless" play and the dominant imagination of hanging out.

Bilal $(25, \mathrm{~m})$ : When they talk about "hanging out" they mean it is bad. But to have fun with friends, play some football, sit somewhere and drink something outside instead of in a bar like the majority does, what's wrong with that? They go sit in a park with a beverage of perhaps $1 €$. Everyone with their own means. I don't think that to go sit in a park with a group of ten people is bad. There are many more people in bars.

Bilal means that not having the money to buy drinks in a bar is one reason to not go there, but he also refers to patterns of exclusion, cultural and social thresholds that erect boundaries between demographic groups in Brussels. A drari such as Bilal is not expected to enter one of the hip bars in the rue Dansaert, only a few $100 \mathrm{~m}$ away from his house.

For young men with migration background or living in the deprived neighbourhoods in the west of Brussels, repeated experiences with exclusion and prejudice outside of their home neighbourhoods coincides with an enhanced attachment to that area, where they are "among themselves". This phenomenon of enhanced attachment to place, which comes hand in hand with a limited mobility in the urban region, can be called territoriality $[38,49]$.

\section{Territoriality}

According to Karsten et al. [16], boys and young men with a migration background, particularly those from the Middle-East and the Maghreb, spend much time outside in their home neighbourhoods. Young people from more affluent families are found less in public space and more in organised leisure activities or at home. This finding relates to a lack of resources and of social and cultural capital among lower-class youth. The limited spatial mobility is seldom identified by the former in a literal way. Alae $(18, \mathrm{~m})$, Marouane $(15, \mathrm{~m})$, Illias $(15, \mathrm{~m})$ and Souhail $(17, \mathrm{~m})$ in Peterbos, for instance, feel they have everything they want inside the housing estate. The only activities that take them outside the area are: a kebab restaurant, a hairdresser, schools and the Westland shopping centre bordering on Peterbos. They sometimes go to the Sint-Guido metro station "pour voir ses potes" (to see their mates), but only when there is nobody within the neighbourhood to meet up with. They barely go to other areas of the city except during the activities of the amateur football competition, but then a grown-up always accompanies them. When asked what they would do if the football pitch in the estate would be closed, one of them answers that he would be sad and eat crisps at home. It does not occur to him that other leisure opportunities await them outside their home neighbourhood. The boys also refer to the fences bordering the estate as infrastructures defending them from outside danger, rather than limiting their freedom to roam more freely. The neighbourhood is being experienced as a safe haven.

In a conversation between Hicham (Sint-Gillis) and Cheb Khaled (Anderlecht) (both 18, m), the latter says he stays in the neighbourhood because "everyone is there". By contrast, the mall in the city centre and the popular Rue Neuve shopping street are part of a territory one prefers to walk through rather than hang out. Rayane $(17, \mathrm{~m})$ : "I go to the Nieuwstraat sometimes, but only to walk through it, not to stay there." Hicham and Cheb Khaled connect this choice to experiences with security staff. The mall, as often as it is researched in youth geography, is not a very common hanging spot among the participants of this study. Rather than wanting to claim that Brussels youngsters do visit malls or shopping streets at all—simply walking around the City 2 mall would contradict that statement- - the observations indicate that "hanging out" as an activity is done much more in the home neighbourhood, in places where they feel at home, where they feel they belong and to a certain extent "own" the place ${ }^{4}$.

4 Interestingly, this type of territorial behaviour among drari has been documented before, by anthropologists such as Rabinow [50] and Fernea [51] who describe how, in their attempt to enter a Moroccan village, they are blocked by the boys 
There are push and pull factors to limited spatial mobility. One factor is the overall limited knowledge of other city regions or of places outside of the city. In my notes during a youth camp I write:

"They gave me compliments on my French, which was nice of them. At the same time one boy asked me "are you from Quebec?" He had heard my accent was different and so he assumed I must be from Canada. They apparently have no idea about what happens in the Northern part of the country. One girl, Christia, has heard of Ghent and that seemed like a miracle." (29 October 2013)

One could surmise that spatial mobility, particularly among poorer inhabitants of the city, also links to the supply of (cheap) public transport. This is not the case in Brussels. The distribution of public transport lines, stops and stations in the poor sickle-shaped area in the west of the city is excellent. In fact, neighbourhoods in the east and in the second ring around the city centre are considerably less connected with public transportation. Neither does the price of public transport play a significant role. At the time of the study, young people from those neighbourhoods seldom paid for riding the metro, tram or bus. From the supply side, it seems, there is no good reason (young) people from the poor crescent would be less mobile.

The elephant in the room is class. From the work of Cailliez et al. [52] we know that young people from wealthier neighbourhood are much more mobile than those from poorer areas. Mobility, it seems, is linked to class and family income. As Gough and Franch's [53] study in Brazil finds, young people from low-income neighbourhoods tend to hang out in the streets of their home area, whereas shopping centres are mainly used by middle-class youth who consider these spaces safer. Interestingly, this study also finds that young people from low-income neighbourhoods experience more spatial freedom because they are less restricted by their parents. At first glance, this may also be the case in Brussels. A majority of the boys (above 14 years old) from low-income areas say that they are allowed to go anywhere, take the metro as they please. However, these same boys' and young men's ignorance about other parts of the city contradicts this finding. "I live in Etterbeek and I don't go tout en haut de Bruxelles just like that. Like Molenbeek for instance, I don't go there. I don't know anybody there" (Younes, 11, m). Young people from the poor sickle-shaped area in the West of Brussels seldom or never visit the more affluent areas of the urban region, because they do not feel comfortable there.

Another factor that contributes to a limited spatial mobility is identified in Watt and Stenson's [54] research into young people's leisure itineraries in Buckinghamshire (UK). In this study, fear and unease about ethnic diversity play an important role, both among middle-class and lower-class youth. In my own research, I found that there is little contact between youth from richer and whiter and from poorer and much more diverse neighbourhoods. A part of this can be traced back to discourses that are reciprocally reproduced. Those from higher income families actively formulate or construct images of neighbourhoods from Anderlecht, Schaarbeek, Molenbeek or Vorst, while these areas are terra incognita for most if not all of them. Many of the youngsters from the lower-middle class residential neighbourhood Jacht-Jourdan actively reproduce, or at least uncritically echo, elements of discourses of the "dirty", "chaotic" and "dangerous" "ghetto". On the other end of the spectrum resides the young person from low-income area Peterbos who feels insecure, has low self- esteem and low cultural capital, enough to not venture into the rest of the city.

The inhabitants of the Gentsesteenweg [in Molenbeek] have as their ultimate horizon the Bourse. It is the incarceration of the imagination and perception of space; a non-mastering of the spatial and the social. 'I am not in place.' The territorial logic is strong. (Andrea Rea quoted in [52]: p. 34; my translation). 
Even other parts of the sickle-shaped area are unknown territory. Higher-income areas, though foreign to these youngsters, are considered hostile and/or boring, and their inhabitants "sales Flamands" (dirty Flemish, a nickname used for middle-class people in Brussels, whether they in fact speak Dutch or not). The rich, suburban areas in the periphery and the gentrified areas of downtown Brussels are mentioned sometimes, but only categorically.

In Sack's [55] (p. 55) original conceptualisation of human territorialisation-defined as "the attempt to affect, influence, or control actions and interactions (of people, things, and relationships) by asserting and attempting to enforce control over a geographic area" - the enhanced attachment to place has transformed in physical or symbolic acts to control an area and defend it against intruders. This is, at first glance, a description of the practices of urban gangs and cannot be extended to "ordinary" urban youth. Indeed, in Lynch's [56] (p. 139) study, young people say that the streets belong to everybody and that they have never been in a situation where they are forced to fight for their place. Most young people in my research consider the "publicity" of public space as primordial, especially since they are often targeted by adults about their use of and behaviour in public space. That also means, of course, that the second part of Lynch's observation cannot be corroborated from the data in Brussels. On the contrary, to have to claim a space from certain groups happens quite regularly. Meryem $(13, \mathrm{f})$ recounts the time when she was asked by an elderly woman to be silent: "I don't appreciate that. Public space is for everyone, not only for her. If she wants silence she should go to her place. And that she doesn't harass me." Luca $(13, \mathrm{~m})$ and Stefano $(14, \mathrm{~m})$, after they have been urged by a store manager to go hang out somewhere else: "There is no sign there that says 'private'. It's a staircase, what could we do wrong? And he didn't even let us finish talking, he simply said to leave."

That places have to be claimed and appropriated almost by definition implies that these places have to be defended, physically or symbolically. Since, as argued above, "microcultures" are groups sharing similar styles, experiences and events and an enhanced attachment to the places they consider their own, territoriality, contestation and conflict are all part of a young urbanite's experiences in public space. Indeed, Pickering et al.'s [38] analysis shows that not only gangs but also other groups of young people engage in territory-building. According to these authors, territoriality consists of close affinity with place, limited spatial mobility, (violent) confrontations with outsiders, symbolical acts of place-making (e.g., tagging and graffiti, see [57]) and the production of "rich, heavily mythologised histories" (p. 945). Making use of space and claiming it as territory can be an almost invisible, affective process, inscribing ownership and "thickness" $[54,58,59]$ into the urban fabric: "by hanging out at the shopping arcades, congregating on street corners, using public squares as cruising corners, playing soccer and so on they physically mark certain areas as 'their' territory" [60] (pp. 107-108). In Pickering et al.'s [38] reading, territoriality is not in the first place a result of exclusion from society and a materialisation of resistance, in the sense that the Birmingham School would interpret it. Rather, enhanced attachment to place leads to territory building, which in turn leads to limited spatial mobility, imposing sanctions on access to leisure, education, employment and social opportunities.

Among the Brussels drari, territoriality as the fight for a place of their own is mostly symbolic. However, some examples of physical conflict for and control of place can be identified: the recurrent fights with police-officers, fire-fighters or other municipal personnel in Molenbeek and Peterbos, for instance, are a good example of this. The territoriality of those neighbourhoods translates in pride, belonging and an inward-looking quality of social control. Parallel with this comes a distrust or hate towards outsiders, particularly if they are representatives of the state; petty crime is usually resolved within the community. From research undertaken in the UK after the 2011 riots we know that "getting back at the police" was a particularly strong motivation among the rioters and looters [61]. Pickering et al.'s [38] reading of territoriality reflects young people's membership processes that socially and spatially demarcate insiders-who are trustworthy-and outsiders-who are either superfluous or threatening. Whereas "subcultures" are not necessarily spatially affiliated, drari have strong territorial ties (and boundaries). Among the drari microculture, spatial dynamics of symbolic territory-building can transform to physical acts of violence, for instance when a national television van is spotted at the 
outskirts of the Peterbos estate. Media coming in to film them as monkeys in the zoo: not much more was needed to spark violence.

However, most examples of territoriality are much more benign. As Alae $(18, \mathrm{~m})$ explains in Peterbos: "in the neighbourhood sometimes there is a conflict with the Turk [the grocery store owner], because we are in front of his store, maybe because the other clients are afraid to enter. But, in fact, everybody knows everybody. In the neighbourhood we all know each other. And the clients say nothing when we are there." This account is interesting for two reasons. Firstly, it speaks about how Peterbos, partly due to its physical outlook (around 20 dilapidated apartment blocks, in an estate bordered by a few roads and some fencing) and partly due to its demographic constellation, is an inward-looking community. This translates easily into a parochial atmosphere characterised by reciprocal familiarity, even if only superficially. This aspect is probably crucial to territory-building. Secondly, what Alae does not seem to "get" is that the way these young people are hanging out in front of the local grocery store, in a semi-circle, stealing quick glances around as if they are engaged in criminal activities, looks imposing to passers-by. Moreover, they occupy one of the "top" spots of the area, slightly elevated with a $360^{\circ}$ view of estate. As an inhabitant of the area (and as a researcher who is hanging out there quite some time himself), one can feel that this space is claimed and owned by these drari, even when they are not around. Of course, the other inhabitants also actively claim or guard the territory, sometimes against the drari when they are being loud late in the evening: "sometimes they throw plastic bottles or eggs towards us from one of the buildings"

Another example is how the territoriality of urban space is heavily gendered. Enhanced attachment to place in lower-class areas is not experienced the same way by boys and girls. Nouhaila $(19, \mathrm{f})$, for example, describes how she feels comfortable and at ease walking around in the Chicago area because she knows all the boys that hang out on the corners. This atmosphere of familiarity and sameness is exactly why Chaimaa $(21, \mathrm{f})$ has a love/hate relationship with the neighbourhood, because she feels the presence of boys on corners is threatening. Clearly, she does not feel she belongs in the neighbourhood with its subtle forms of territoriality and social control. "I'm used to going outside and getting by, and find my way in the city. I do not have the habit of staying in one place; I like to leave the neighbourhood." Many of the girls are also aware that there are gender differences in terms of mobility:

Me: Do you think girls are as free as boys?

Chaimaa: No. I think you are right. It has something to do with the trust parents have in them and that a girl will be more inclined to stay at home and help in the household. While a boy is freer, he leads his life...

Me: Are there specific places in the neighbourhood you don't feel safe?

Chaimaa: Street corners, cafes, places where you can find the boys of the neighbourhood.

Me: Nouhaila told me she feels safe in the neighbourhood because she knows these guys she meets at street corners. Is it different with you?

Chaimaa: Depends. If it is family or one of your nephews. I don't have any family so it annoys me. I don't have any big brothers so they would more easily harass me. ( ... ) When girls want to go outside they cannot stay in the neighbourhood. They do not like to hang around before their doorstep. I remember when I was little I played in front of my house constantly. Until I was 15 or so. Now I really have to leave the neighbourhood. That's good, because I learn stuff that way, but sometimes I'm afraid if I bring a [female] friend they will harass us again. It annoys me.

The type of masculine performance at street corners, squares or entrances of metro stations described by Chaimaa has been documented before [62-64]. "Masculinity", first conceptualised by Connell [65], refers to "the repertoire of exaggerated practices and behaviors adopted by marginalized young men in response to their powerlessness, anger and frustration over their exclusion from the dividends of hegemonic masculinity" [62] (p. 583). Interestingly, the author mentions mobility as one example of the dividends from which these men are excluded. It is my argument, however, that a part of this exclusion is internalised as territoriality and enhanced attachment to place. Majors and Billson [66] 
(p. 5) talk in this regard in a similar manner about the "cool pose", described as a "distinctive coping mechanism that serves to counter ( ... ) the dangers that black males encounter on a daily basis. As a performance, cool pose is designed to render the black male visible and to empower him ( . . ) [It] is an ego booster." Although this study talks about the situation of black males in the US, the situation of the drari in Brussels is, socio-economically and discursively, to a certain extent comparable. Here as well, young men with a migration background fight economic discrimination and prejudice, as well as actual threats and dangers. While we could consider the actions of these men in public space as strategies to oppress women and control the female members of their communities, they are also victims of feelings of powerlessness and insecurity, due to the circumstances of structural social and economic vulnerability, discrimination and everyday racism.

Research has shown that feelings of belonging, street-literacy and spatial knowledge have positive effects in terms of growing up in the urban environment, identity construction and self-esteem, while also serving as a safety net $[43,67,68]$. The "warmness" of the home neighbourhood is obviously also why young people would limit their spatial range, weighing it against the "coldness" of the world out there. It is not a coincidence that the territorial behaviour described in the above paragraphs occurs most in neighbourhoods in which public spaces are dominated by one demographic group, which translates into a feeling of "everyone is like me." As Bilal $(25, \mathrm{~m})$ puts it: "it is easier to live together with people who have the same ethnicity or religion."

This cosy feeling of belonging in the home neighbourhood is reinforced by fear and hostility coming from the outside, retold in intergenerational mythologies of the drari microculture, by the almost daily reality of police violence and harassment [69], discrimination on the housing market, the terrible situation of the Brussels education system and racism among employers. Although the deprived neighbourhoods in Brussels, contrary to Paris, are located in the city centre, young people from these areas "speak of an experience of confinement to their neighbourhood: not daring to move from one block to another, from one sub-neighbourhood to another, from the neighbourhood, etc." [69] (p. 2). This feeling is reinforced by subtle cues of non-belonging in that outside world, through surveillance and ambient power [70] of shopping areas, shiny, imposing office towers, security guards, cleanliness and order. These areas are not always explicitly hostile, but often an atmosphere is produced that conveys one message: "no loitering".

"The metro station feels rather 'cold'. The capacity for thickness seems much smaller in a place like this. There are small groups but you see their presence is functional: they're waiting to catch a metro train. What's more: there must be many cameras, there are the entrance gates. It's a place of passage." (30 September 2015)

Non-belonging is even reinforced by objects that are not present, such as the removed benches from the field just outside the Peterbos estate.

\section{Discussion and Conclusions}

Can we categorise the drari culture as either a subculture or a post-subculture? There are arguments for both. Young people who hang out do not necessarily adopt an anti-establishment attitude, on the contrary. For instance, the vast majority of young people interviewed hold socially conforming opinions about control, rules and infrastructures such as surveillance cameras. Othmane $(12, \mathrm{~m})$ agrees that "there are cameras for when someone steals or something", although he also remarks that "children shouldn't be controlled too much", while Faiza and Elizabeth (both 18, f) say that they are already constantly supervised and controlled "so cameras won't make a difference." Cameras and other types of surveillance are simply an extension of the control they are already undergoing in other milieus of socialisation such as in school, organised leisure or at home. To Rayane $(17, \mathrm{~m})$ cameras come across as something normal but he would not like one in his own street. "I don't see the purpose of a camera; it needs to stay somewhat private, no?" Interestingly, he suggests that he feels strongly about the 
neighbourhood he lives in, that he feels he really belongs there and that cameras would change that. The same caveat is formulated by Alae $(18, \mathrm{~m})$ in Peterbos.

The drari should also be distinguished from classic subcultures because the latter are often portrayed as a dynamic of intergenerational conflict [39] which cannot be truly said about the former. The young drari interviewed in deprived areas such as Molenbeek or Peterbos speak highly of their older brothers, uncles or mothers while they also claim that in the home neighbourhood "everybody knows everybody". The four adolescents in Peterbos, for instance, talk about how they hang out in front of the local grocery store: "he doesn't like that we are there, but we don't have a place to go. When it rains we go to the washing shop next door." When asked about conflicts with adults in the nearby Westland shopping centre, they say that "conflicts are really rare, sometimes with the police on the parking space." Moreover, most of the examples of conflict the participants talk about are between peers, often in the context of school. Conflicts with adults are much less common. Even if young people talk about intergenerational conflicts in their accounts, still their confessions of love and intimacy vis-à-vis their own neighbourhood is witness to its relative peacefulness.

On the other hand, inequality and resistance as well as other class conflicts can be found in the drari microcultures. The activity itself, hanging out, is one they do out of necessity: many of the drari live in crowded apartments and do not have the financial means or the social and cultural capital for organised leisure. This activity can also be interpreted as a subconscious resistance to the dominant norm in society that identifies "idle hands" as "the devil's workshop". As Corrigan [71] writes, doing nothing is the largest and most complex of youth "subcultures". Boredom and doing nothing ought to be considered resistance against the dominant expectation of having to act busy and "do something useful with your time." Similarly, hanging out and doing nothing can be considered a transgression of the informal rules of stranger interaction in public space [72]. In that sense, the observations described in this paper show that drari microcultures do challenge prescriptions from dominant groups regarding "proper" behaviour in public space. Even in the absence of "resistance" in a literal sense or unlike the classic subcultural studies of outspoken, political artforms such as hip-hop or graffiti, they engage in everyday politics of public space [73]. These everyday transgressions are the kind of unnoticeable subtleties Malbon [13] talks about in his description of clubbing post-subcultures, but they also echo Lefebvre's [34] insight that the body can function as a site of resistance against the discourse of power in space.

Are the drari then manifestations of a post-subculture, lifestyle or neo-tribe? While some commentators would argue that individual identity in postmodern times has replaced class membership, this is definitely not true in the case of the drari microcultures of Brussels. Identity, idiosyncratic or not, is constructed from the set of social relations and meanings surrounding them, including the relation with dominant groups and discourses. It is not a coincidence that most if not all drari are lower-class young people, inhabitants of low-income neighbourhoods and members of subaltern social groups. Their relation to dominant groups reinforces the inward-looking quality of their communities and microcultures since they feel they do not belong in large parts of the urban region. They are consistently negatively portrayed in the media and there is little political representation of their particular neighbourhoods. Thus, their practices of territory-building are the result of two interrelated phenomena: pride and belonging to the home neighbourhood on the one hand and the stigmatisation and hostility experienced elsewhere.

Furthermore, the adherence to idiosyncratic styles among the Brussels drari in terms of dress-code, music preference or the slang used in the street shows that, even in 21st century youth cultures, there may be a form of "subcultural regulation" as Blackman [4] calls it. Shifting boundaries or hybridity are no counter-arguments to the existence of these type of externalities typical of group processes. Moreover, while some authors report about the mobility and hybridity of contemporary post-subcultural youth $[25,27]$ they may overlook that mobility and hybridity are qualities that demand a social and cultural capital not every young person has, let alone that they can "exhaust subcultural style and move to a different one" [4] (pp. 25-26). 
Can we categorise the drari microculture as either a subculture or a post-subculture? There are arguments for both, but the answer is "no". The drari are not a "subculture" in the classic sense because membership is much more fluid and multiple and because these microcultures cannot always be understood in terms of resistance against or "sub" to a dominant culture. The drari also cannot be captured using the post-subcultural frame of reference, since "post-subcultures" are inherently linked to identification with music (neo-tribes, scenes; e.g., Huq's [74] study of hip hop, dance, bhangra, rap, grunge and Britpop) or fashion (lifestyles), they are highly individualised and are closely linked to consumerism. There are indeed observations to be made about their music preferences or their choice of clothes (which we could definitely call mestizo, mélange or assemblage) but these elements are not defining characteristics in the construction of their social identity.

With Kintrea et al. [37] and Matthews et al. [32], I would like to argue instead for focusing on "the locations they make their own". In the case of the drari, this leads to the insight that they occupy rather small social, symbolic and mental spaces, limiting their range of movement largely to the home neighbourhood. This territoriality is a phenomenon that is usually not seen among middle-class youth; territoriality and spatial mobility correlate highly with class. As a result of these young people's restricted spatial mobility transitions to adult life are inhibited, as, for example, by restricting access to education. Growing up in specific underprivileged areas often also negatively affects social mobility. Conversely, being in a more disadvantaged position structurally makes it more likely that individuals will engage in localised sub- or microcultures (see [9]). ${ }^{5}$

To a certain extent, drari's spatial practices remind of the phenomenon of urban youth gangs and their turf and neighbourhood attachment [77-79]. However, gang-like territoriality, understood as "a monopolistic control over geographical space, exercised for economic gain" [80] (p. 970) usually involving rather explicit violence, does not apply to the phenomena observed in Brussels. ${ }^{6}$ While urban gangs and drari microcultures share a lived experience of limited spatial autonomy with disastrous effects, the focus on territory-building also enables research into youth microcultures, gangs or deviance in public space to move beyond the traditional criminological gaze by incorporating theories of space, class and identity.

To conclude, the microculture concept, with its choice for studying small groups as a locus of analysis and its sensitivity to scale and place, acknowledges the fluidity and heterogeneity of individual identity among the drari as well as the group processes. The meso-sociological analysis of a microculture is also essentially different from the (post-)subcultural approach because, even if subcultural empirical work sometimes focuses on equally small youth groups, it usually purports to make statements about social structure in general. At the same time, this approach does not minimalise the extent to which the drari's lives are the result of structural inequality inscribed in the built environment and which shows in their socio-spatial mobility. Furthermore, it also allows for an understanding of their group solidarity and belonging beyond deviance or crime [81].

Funding: This research was funded by Fonds voor Wetenschappelijk Onderzoek (FWO) grant number [G063312N]. Conflicts of Interest: The authors declare no conflict of interest.

\section{References}

1. Parsons, T. Age and sex in the social structure of the United States. Am. Sociol. Rev. 1942, 7, $604-616$. [CrossRef]

2. Muncie, J. Youth E Crime, 3rd ed.; Sage: London, UK, 2009.

3. Maira, S.; Soep, E. (Eds.) Introduction. In Youthscapes, the Popular, the National, the Global; University of Pennsylvania Press: Philadelphia, PA, USA, 2005.

5 However, as research into migration and transnationalism has shown, localised culture, particularly among migrants, is always to a certain extent transnational [75] or trans-local [76] and the same can be said about subcultures [4] (p. 16).

6 Of course, some research indicates that youth gangs in Brussels do exist, e.g., Van Hellemont and Densley [48]. 
4. Blackman, S.J. Youth subcultural theory: A critical engagement with the concept, its origins and politics, from the Chicago School to postmodernism. J. Youth Stud. 2005, 8, 1-20. [CrossRef]

5. Cohen, P. Sub-cultural conflict and working class community. In Working Papers in Cultural Studies. No.2, 2nd ed.; Hall, S., Hobson, D., Lowe, A., Willis, P., Eds.; University of Birmingham: Birmingham, UK, 1972.

6. Tajfel, H.; Billig, M.G.; Bundy, R.P.; Flament, C. Social categorization and intergroup behaviour. Eur. J. Soc. Psychol. 1971, 1, 149-178. [CrossRef]

7. Jenkins, R. Social Identity, 3rd ed.; Routledge: London, UK, 2008.

8. Hall, S.; Jefferson, T. Resistance Through Rituals. Youth Subcultures in Post-War Britain, 3rd ed.; Routledge: London, UK, 1993.

9. McCulloch, K.; Stewart, A.; Lovegreen, N. We just hang out together: Youth cultures and social class. J. Youth Stud. 2006, 9, 539-556. [CrossRef]

10. Daskalaki, M.; Mould, O. Beyond urban subcultures: Urban subversions as rhizomatic social formations. Int. J. Urban Reg. Res. 2013, 37, 1-18. [CrossRef]

11. Jenks, C. Subculture. The Fragmentation of the Social, 3rd ed.; Sage Publications: Thousand Oaks, CA, USA, 2005.

12. Thornton, S. Club Cultures: Music, Media and Subcultural Capital, 3rd ed.; Polity Press: Cambridge, UK, 1995.

13. Malbon, B. Clubbing: Consumption, identity and the spatial practice of every-night life. In Cool Places: Geographies of Youth Culture, 2nd ed.; Skelton, T., Valentine, G., Eds.; Routledge: London, UK, 1998.

14. Bonnett, A. The transgressive geographies of daily life. Transgressions J. Urban Explor. 1996, 2/3, $20-37$.

15. Hörschelmann, K.; van Blerk, L. Children, Youth and the City, 3rd ed.; Routledge: Abingdon, UK, 2012.

16. Karsten, L.; Kuiper, E.; Reubsaet, H. Van de Straat? De Relatie Jeugd en Openbare Ruimte Verkend, 3rd ed.; Van Gorcum: Assen, The Netherlands, 2011.

17. Clarke, G. Defending Ski-Jumpers: A Critique of Theories of Youth Subcultures, 3rd ed.; Stencilled Paper; Centre for Contemporary Cultural Studies, University of Birmingham: Birmingham, UK, 1982.

18. Amit-Talai, V. Youth Cultures: A Cross Cultural Perspective. In The 'Multi' Cultural Youth, 2nd ed.; Amit-Talai, V., Wulff, H., Eds.; Routledge: London, UK, 1995; pp. 223-233.

19. Willis, P. Pop Music and Youth Groups. Ph.D. Thesis, Centre for Contemporary Cultural Studies, University of Birmingham, Birmingham, UK, 1972.

20. Hannerz, U. Cultural Complexity. Studies in the Social Organization of Meaning, 3rd ed.; Columbia University Press: New York, NY, USA, 1992.

21. Redhead, S. Subculture to Clubcultures, 3rd ed.; Blackwell: Oxford, UK, 1997.

22. Hollands, R. Division in the dark: Youth cultures, transitions and segmented consumption spaces in the night-time economy. J. Youth Stud. 2002, 5, 153-173. [CrossRef]

23. Muggleton, D. Inside Subculture: The Postmodern Meaning of Style, 3rd ed.; Bloomsbury Academic: London, UK, 2000.

24. Miles, S. Youth Lifestyles in a Changing World, 3rd ed.; Open University Press: Philadelphia, PA, USA, 2000.

25. Straw, W. Systems of articulation, logics of change: Communities and scenes in popular music. Cult. Stud. 1991, 5, 368-388. [CrossRef]

26. Peterson, R.A.; Bennett, A. Introducing music scenes. In Music Scenes: Local, Trans-Local, Virtual, 2nd ed.; Bennett, A., Peterson, R.A., Eds.; Vanderbilt University Press: Nashville, TN, USA, 2004.

27. Bennett, A. Subcultures of neo-tribes? Rethinking the relationship between youth, style and musical taste. Sociology 1999, 33, 599-617.

28. Harrington, B.; Fine, G.A. Opening the "Black Box": Small Groups and Twenty-First-Century Sociology. Soc. Psychol. Q. 2000, 63, 12-323. [CrossRef]

29. Fine, G.A. Small groups and culture creation: The idioculture of little league baseball teams. Am. Sociol. Rev. 1977, 44, 733-745. [CrossRef]

30. Wulff, H. Twenty Girls: Growing up, Ethnicity and Excitement, 3rd ed.; Almqvist and Wiksell International: Stockholm, Sweden, 1988.

31. Wulff, H. Introducing Youth Culture in its Own Right. In Youth Cultures: A Cross Cultural Perspective, 2nd ed.; Amit-Talai, V., Wulff, H., Eds.; Routledge: London, UK, 1995; pp. 63-80.

32. Matthews, H.; Limb, M.; Percy-Smith, B. Changing worlds: The microgeographies of young teenagers. Tijdschr. Voor Econ. Soc. Geogr. 1998, 89, 193-202. [CrossRef] 
33. Blommaert, J.; Varis, P. Enoughness, Accent and Light Communities: Essays on Contemporary Identities. Tilburg Pap. Cult. Stud. 2015, 139, 16-30. Available online: https://www.tilburguniversity.edu/upload/ 5c7b6e63-e661-4147-a1e9ca881ca41664_TPCS_139_Blommaert-Varis.pdf (accessed on 12 September 2016).

34. Lefebvre, H. The Production of Space, 3rd ed.; Nicholson-Smith, D., Translator; Blackwell Publishing: Oxford, UK, 1991.

35. Elden, S. There is a politics of space because space is political. Henri Lefebvre and the production of space. Radic. Philos. Rev. 2007, 10, 101-116. [CrossRef]

36. Shildrick, T.; Blackman, S.; MacDonald, R. Young people, class and place. J. Youth Stud. 2009, 12, 457-465. [CrossRef]

37. Kintrea, K.; Bannister, J.; Pickering, J.; Reid, M.; Suzuki, N. Young People and Territoriality in British Cities, 3rd ed.; Joseph Rowntree Foundation: York, UK, 2008.

38. Pickering, J.; Kintrea, K.; Bannister, J. Invisible walls and visible youth: Territoriality among young people in British cities. Urban Stud. 2012, 49, 945-960. [CrossRef]

39. Cohen, P. Rethinking the Youth Question: Education, Labour and Cultural Studies, 3rd ed.; Macmillan: London, UK, 1997.

40. Hermia, J.-P. Baromètre démographique 2017 de la Région de Bruxelles-Capitale. Focus 22. 2018. Available online: http://statistics.brussels/files/publications/focus-de-libsa/FOCUS-22-FR-final.pdf (accessed on 12 September 2017).

41. Corijn, E.; Vloeberghs, E. Brussel! 3rd ed.; VUBPress: Belgium, Brussel, 2009.

42. Lynch, K. A Theory of Good City Form, 3rd ed.; MIT Press: Cambridge, UK, 1981.

43. Pyyry, N. Hanging Out with Young People, Urban Spaces and Ideas: Openings to Dwelling, Participation and Thinking. Academic Dissertation (Unpublished); Faculty of Behavioural Sciences, University of Helsinki: Helsinki, Finland, 2015.

44. Breitbart, M. Dana's mystical tunnel: Young people's designs for survival and change in the city. In Cool Places: Geographies of Youth Cultures, 2nd ed.; Skelton, T., Valentine, G., Eds.; Routledge: London, UK, 1998; pp. 306-329.

45. Salois, K. Make some noise, drari: Embodied listening and counterpublic formations in Moroccan hip hop. Anthropol. Q. 2014, 87, 1017-1048. [CrossRef]

46. Witulski, C. Light rhythms and heavy spirits: entertaining listeners through gnawa musical and ritual adaptations in Morocco. Ethnomusicol. Forum 2016, 25, 172-190. [CrossRef]

47. De Backer, M. Regimes of visibility: Hanging out in Brussels' public spaces. Space Cult. 2018, 22, 308-320. [CrossRef]

48. Van Hellemont, E.; Densley, J.A. Gang glocalization: How the global mediascape creates and shapes local gang realities. Crime Media Cult. 2019, 15, 169-189. [CrossRef]

49. Sack, R. Human territoriality: A theory. Ann. Assoc. Am. Geogr. 1983, 73, 55-74. [CrossRef]

50. Rabinow, P. Reflections on Fieldwork in Morocco, 3rd ed.; University of California P: Berkeley, CA, USA, 1977.

51. Fernea, E.W. A Street in Marrakech, 3rd ed.; Doubleday: New York, NY, USA, 1980.

52. Cailliez, J.; Samarcande, A.M.O.; Inter-Environnement Bruxelles \& SOS Jeunes. Bruxelles à Dos? L'appropriation de L'espace Urbain Bruxellois Par des Jeunes de Diffárents Quartier, 3rd ed.; Intern-Environnement Bruxelles: Bruxelles, Belgium, 2008. Available online: http://www.ieb.be/Jeunes-en-ville-Bruxelles-a-dos (accessed on 18 August 2019).

53. Gouch, K.; Franch, M. Spaces of the Street: Socio-spatial Mobility and Exclusion of Youth in Recife. Child. Geogr. 2005, 3, 149-166. [CrossRef]

54. Watt, P.; Stenson, K. The street, it's a bit dodgy around here. In Cool Places: Geographies of Youth Cultures, 2nd ed.; Skelton, T., Valentine, G., Eds.; Routledge: London, UK, 1998; pp. 249-266.

55. Sack, R. Homo Geographicus: A Framework for Action, Awareness, and Moral Concern, 3rd ed.; Johns Hopkins: Baltimore, MD, USA, 1997.

56. Lynch, K. (Ed.) Growing Up in Cities, 3rd ed.; MIT Press: Cambridge, UK, 1977.

57. Brighenti, A.M. At the wall: Graffiti writers, urban territoriality, and the public domain. Space Cult. 2010, 13, 315-332. [CrossRef]

58. Casey, E.S. Between Geography and Philosophy: What Does It Mean to Be in the Place-World? Ann. Assoc. Am. Geogr. 2001, 91, 683-693. [CrossRef] 
59. De Backer, M.; Pavoni, A. Through thick and thin: Young people's affective geographies in Brussels' public space. Emot. Soc. Space 2018, 27, 8-15. [CrossRef]

60. Pile, S.; Brook, C.; Mooney, G. (Eds.) Unruly Cities: Order/Disorder, 3rd ed.; Routledge: London, UK; New York, NY, USA, 1999.

61. Morrell, G.; Scott, S.; McNeish, D.; Webster, S. The August Riots in England. Understanding the Involvement of Young People, 3rd ed.; NatCen: London, UK, 2011.

62. Bronlow, A. A geography of men's fear. Geoforum 2004, 36, 581-592. [CrossRef]

63. Hopkins, P. Youthful Muslim masculinities: Gender and generational relations. Trans. Inst. Br. Geogr. 2006, 31, 337-352. [CrossRef]

64. Gorman-Murray, A. Urban homebodies: Embodiment, masculinity and domesticity in inner Sydney. Geogr. Res. 2013, 51, 137-144. [CrossRef]

65. Connell, R.W. Masculinities, 3rd ed.; University of California Press: Berkeley, CA, USA, 1995.

66. Majors, R.; Billson, J.M. Cool Pose: The Dilemmas of Black Manhood in America, 3rd ed.; Lexington Books: New York, NY, USA, 1992.

67. Cahill, C. Street literacy: Urban teenagers' strategies for negotiating their neighbourhood. J. Youth Stud. 2000, 3, 251-277. [CrossRef]

68. De Visscher, S.; Bouverne-De Bie, M. Recognizing public space as a co-educator: Children's socialization in Ghent. Int. J. Urban Reg. Res. 2008, 32, 604-616. [CrossRef]

69. Mazzocchetti, J. Feelings of injustice and conspiracy theory. Representations of adolescents from an African migrant background (Morocco and sub-Saharan Africa) in disadvantaged neighbourhoods of Brussels. Bruss. Stud. 2012, 63. Available online: http://journals.openedition.org/brussels/1123 (accessed on 9 May 2019). [CrossRef]

70. Allen, J. Ambient power: Berlin's Potsdamer Platz and the seductive logic of public spaces. Urban Stud. 2006, 43, 441-455. [CrossRef]

71. Corrigan, P. [1976] Doing nothing. In Resistance Through Rituals. Youth Subcultures in Post-War Britain, 2nd ed.; Hall, S., Jefferson, T., Eds.; Routledge: London, UK, 2000; pp. 102-104.

72. Lofland, L.H. The Public Realm. Exploring the City's Quintessential Social Territory, 3rd ed.; Aldine Transaction: New Brunswick, NB, Canada; London, UK, 1998.

73. De Backer, M.; Dijkema, C.; Hörschelmann, K. Everyday politics of public space-prefigurative, affective and performative perspectives on privacy, publicness and belonging. Space Cult. 2019, 22, 240-249. [CrossRef]

74. Huq, R. Beyond Subculture. Pop, Youth and Identity in a Postcolonial World, 3rd ed.; Routledge: London, UK, 2006.

75. Basch, L.G.; Glick Schiller, N.; Blanc-Szanton, C. Nations Unbound: Transnational Projects, Post-Colonial Predicaments, and De-Territorialized Nation-States, 3rd ed.; Gordon and Breach: Langhorne, PA, USA, 1994.

76. Conradson, D.; Mckay, D. Translocal Subjectivities: Mobility, Connection, Emotion. Mobilities 2007, 2, 167-174. [CrossRef]

77. Thrasher, F. The Gang, 3rd ed.; University of Chicago Press: Chicago, IL, USA, 1927.

78. Cohen, A.K. Delinquent Boys, 3rd ed.; The Free Press: Glencoe, IL, USA, 1955.

79. Parker, H. View from the Boys: A Sociology of Down-Town Adolescents, 3rd ed.; David and Charles Holding: Newton Abbot, UK, 1974.

80. Hagedorn, J. People and Folks: Gangs, Crime and the Underclass in a Rust Belt City, 3rd ed.; Lake View Press: Chicago, IL, USA, 1988.

81. Fraser, A. Street habitus: Gangs, territorialism and social change in Glasgow. J. Youth Stud. 2013, 16, 970-985. [CrossRef]

(C) 2019 by the author. Licensee MDPI, Basel, Switzerland. This article is an open access article distributed under the terms and conditions of the Creative Commons Attribution (CC BY) license (http://creativecommons.org/licenses/by/4.0/). 